\title{
Intraspecific variation among isolates of the entomopathogenic nematode Steinernema feltiae from Bull Island, Ireland
}

\author{
Alec Rolston ${ }^{1, *}$, Conor Meade ${ }^{2}$, Stephen Boyle $^{3}$, Thomae Kakouli-Duarte ${ }^{3}$ \\ and Martin DOWNES ${ }^{2}$ \\ ${ }^{1}$ School of Biological Sciences, Flinders University, GPO Box 2100, Adelaide, South Australia 5001, Australia \\ ${ }^{2}$ Institute of Bioengineering and Agroecology, National University of Ireland Maynooth, Co. Kildare, Ireland \\ ${ }^{3}$ Department of Science and Health, Institute of Technology Carlow, Kilkenny Road, Carlow, Ireland
}

Received: 12 June 2007; revised: 19 August 2008

Accepted for publication: 19 August 2008

\begin{abstract}
Summary - The application of large numbers of entomopathogenic nematodes (EPN) to control insect pests of agriculture is likely to have an impact on the local EPN fauna, yet little is known about the intraspecific relationships between EPN populations, particularly with regard to phylogeny and outbreeding. Here we assess the fitness, with regards to fecundity, host insect mortality and time taken to produce progeny, of isolates of Steinernema feltiae from Bull Island, Ireland. Exon-primed, intron-crossing (EPIC) PCR was used to examine intraspecific phylogenies between $S$. feltiae isolates, and identified up to three possible colonisation events of Bull Island. EPIC-PCR grouped two isolates, 33.D.(2) and 59.F.(2), separately from the remaining ten S. feltiae isolates These same two isolates consistently performed poorly in all fitness assessments. Following the crossbreeding of all isolates in Galleria mellonella, the number of host cadavers exhibiting emerging infective juveniles was significantly fewer than expected and there were significant differences between isolates in the number of days until progeny were observed. Host insect mortality varied between 40 and $87 \%$. Such intraspecific variation may be a result of adaptation to different microhabitats of Bull Island, which in turn may be accentuated by laboratory culture practices.
\end{abstract}

Keywords - EPIC-PCR, fitness, insect, intron, progeny, variation.

Due to their apparently large host range, their specificity to insects and their speed of kill, some species of entomopathogenic nematodes (EPN) are traded globally as classical, inundative and augmentative biological control agents (Peters, 1996). The application of these nematodes into local systems is likely to have a great impact on the general soil fauna as well as local populations of EPN (Somasekhar et al., 2002). However, little is known about the interactions of local intraspecific populations of EPN, particularly with regard to phylogenetic relationships and out-breeding potential.

Molecular techniques are often employed for the taxonomic identification of EPN isolates (e.g., Smits et al., 1991; Joyce et al., 1994) as morphological identification is rarely straightforward (Reid et al., 1997). Such techniques are being used with increasing frequency to infer interspecific EPN phylogenetic relationships (e.g., Liu \& Berry, 1996; Liu et al., 1997, 2000; Reid et al., 1997; Szalanski et al., 2000; Nguyen et al., 2001). However, it is rare that phylogenetic patterns or heirarchical structures have been inferred for same-species isolates (Blouin et al., 1999; Dillon et al., 2008). The targeting of introns in highly conserved nuclear genes, such as $\beta$-tubulin, is useful for identifying high levels of neutral variation within intraspecific populations (Lessa, 1992; France et al., 1999). Exon-primed, intron-crossing (EPIC) primers amplify DNA segments that are usually under lax selective control and so exhibit potentially high rates of sequence divergence that can be informative in studying population structure and genetic diversity, for example, in organisms as diverse as marine shrimp (France et al., 1999), fruit flies (He \& Haymer, 1997) and humpback whales (Palumbi \& Baker, 1994).

The fitness of EPN infective juveniles (IJ) is frequently measured by virulence and reproductive potential (Fenton \& Hudson, 2002; Somasekhar et al., 2002; Shapiro-Ilan et al., 2005) but the ability to survive temperature and desiccation extremes, motility and response to host cues

\footnotetext{
*Corresponding author, email: alec.rolston@flinders.edu.au
} 
are also likely to be important factors (e.g., Grewal et al., 1996; Shapiro et al., 1996; Somasekhar et al., 2002; Wang \& Grewal, 2002). Laboratory culture of EPN may have detrimental effects on laboratory populations due to, for example, selection under artificial conditions and inbreeding depression (Stuart \& Gaugler, 1996; Bilgrami et al., 2006). Costa et al. (2007) state that factors such as the virulence of the symbiotic bacteria, species of host used, concomitant infection with another organism, and the number of penetrated IJ, can affect the multiplication potential of EPN.

Of the three species of EPN found in Ireland (Griffin et al., 1991), Steinernema feltiae and Heterorhabditis downesi co-exist on Bull Island, Dublin Bay, Ireland, although EPN distribution throughout the dune system is species-dependent (Rolston et al., 2005). This study investigates the intraspecific variation among isolates of S. feltiae from Bull Island (Rolston et al., 2005) in terms of fitness, relative infectivity, outbreeding potential and fecundity. As a means of establishing if there is a genetic basis for variance in the sample set, phylogenetic relationships between isolates are also assessed using EPIC-PCR of the $\beta$-tubulin gene region.

\section{Materials and methods}

\section{NEMATODE SAMPLES AND STOCK ISOLATES}

Table 1 lists the isolates of $S$. feltiae used in the experimental analyses. To obtain stock isolates, ten Galleria mellonella larvae were placed into a $9 \mathrm{~cm}$ diam. Petri dish lined with $9 \mathrm{~cm}$ diam. filter paper. A $2 \mathrm{ml}$ suspension of isolate UK76 (1000 nematodes $\mathrm{ml}^{-1}$ ) was added to the filter paper and the dish stored at $20^{\circ} \mathrm{C}$ for 5 days. This was repeated for the remaining isolates listed in Table 1. After 5 days, any dead G. mellonella were placed onto separate White traps (White, 1927). Twenty-one days after first infection, for each isolate, emerged IJ were pooled and stored as stock isolates $\left(1000 \mathrm{IJ} \mathrm{ml}^{-1}\right)$ at $9^{\circ} \mathrm{C}$ until further use.

\section{SPECIES IDENTIFICATION}

Following morphological identification (Gaugler \& Kaya, 1990; Griffin, pers. comm.), all isolates listed in Table 1 were confirmed as $S$. feltiae after the production of viable offspring following successful crossing with UK76 as follows. One IJ from each of two isolates to be crossed were removed separately from their container by pooter and placed into $20 \mu \mathrm{l}$ of distilled water. The two nematodes were then removed using a $5 \mu$ l SGE syringe with plunger (SGE Europe, Milton Keynes, UK) and injected into a single late instar G. mellonella larva behind the last pro-leg. The syringe was checked to ensure both nematodes had been injected into the insect before being washed once in $70 \%$ alcohol and then twice in distilled water. The G. mellonella larva was then placed in a $6 \mathrm{~cm}$ diam. Petri dish lined with moist $5.5 \mathrm{~cm}$ filter paper and stored at $20^{\circ} \mathrm{C}$ for 5 days. The dead larva was then placed on a White trap and stored at $20^{\circ} \mathrm{C}$ until emerging IJ were observed in the trap water. There were 20 replicates per cross.

Table 1. Isolates of Steinernema feltiae used in the EPIC-PCR analysis of the $\beta$ tubulin intron. Asterisks indicate isolates used in all fitness assessment experiments.

\begin{tabular}{ll}
\hline Isolate & Origin \\
\hline Kildare & Steinernema feltiae from Co. Kildare, Ireland \\
Carlow & S. feltiae from Co. Carlow, Ireland \\
1.E.(1)* & Bull Island, isolated August 2002 (Rolston et al., 2005) \\
2.G.(1) & Bull Island, isolated August 2002 (Rolston et al., 2005) \\
4.G.(1) & Bull Island, isolated August 2002 (Rolston et al., 2005) \\
33.D.(2)* & Bull Island, isolated August 2002 (Rolston et al., 2005) \\
35.C.(1) & Bull Island, isolated August 2002 (Rolston et al., 2005) \\
59.F.(2)* & Bull Island, isolated August 2002 (Rolston et al., 2005) \\
65.D.(1) & Bull Island, isolated August 2002 (Rolston et al., 2005) \\
74.D.(1) & Bull Island, isolated August 2002 (Rolston et al., 2005) \\
74.J.(1) & Bull Island, isolated August 2002 (Rolston et al., 2005) \\
77.J.(1)* & Bull Island, isolated August 2002 (Rolston et al., 2005) \\
UK76* & Commercial UK S. feltiae (Microbio, Cambridge, UK) \\
\hline
\end{tabular}




\section{ASSESSMENT OF CROSS BREEDING}

Four Bull Island isolates were selected for cross breeding studies, two from the extremities of the sample area of Rolston et al. (2005), isolates 1.E.(1) and 77.J.(1), and two from the middle region of the same sample area, isolates 33.D.(2) and 59.F.(2). The distances between soil cores from which the Bull Island isolates were obtained are shown in Table 2. The UK isolate, UK76, was also included in this study. These five isolates were crossed with themselves (selfed) and each other (out-crossed) as described above. There were 40 replicates per isolate cross, making 600 crosses in total. Comparisons between actual and expected number of emergences were performed using one-proportion tests. The number of progeny produced, the time taken to produce progeny, and insect mortality were all measured to assess the success of each cross.

\section{Progeny numbers}

The numbers of progeny found in the water of each White trap as a result of the above crosses were recorded as follows. The White trap IJ suspension was collected 7 days after emergence was first observed. Each White trap was rinsed twice with water to ensure the collection of IJ. The IJ suspension from a single G. mellonella cadaver was placed into individual $100 \mathrm{ml}$ graduated cylinders and inverted three times to ensure thorough mixing. Twenty $\mathrm{ml}$ of the suspension was pipetted onto an inverted $6 \mathrm{~cm}$ diam. Petri dish lid, and the number of IJ counted. An average number of IJ per $20 \mu \mathrm{l}$ was calculated after five counts, and the total number of IJ $100 \mathrm{ml}^{-1}$ (or total number of IJ emerged) calculated. This estimated the total emergence of cross-progeny per cadaver per cross after 7 days. This was repeated for each cadaver from which IJ emerged. The totals calculated for each cadaver per cross were combined to produce an overall estimate of the mean number of IJ emerged from each cross.

Table 2. Calculated straight line distances $(m)$ between cores from which the isolates were obtained on Bull Island.

\begin{tabular}{lcccc}
\hline Isolate & \multicolumn{4}{c}{ Isolate } \\
\cline { 2 - 5 } & 1.E.(1) & 33.D.(2) & 59.F.(2) & 77.J.(1) \\
\hline 1.E.(1) & 0 & 320.16 & 580.09 & 761.64 \\
33.D.(2) & & 0 & 260.77 & 444.07 \\
59.F.(2) & & & 0 & 184.39 \\
77.J.(1) & & & & 0
\end{tabular}

Vol. 11(3), 2009

\section{Time taken to produce progeny}

The isolates used in this study were 1E.(1), 33.D.(2), 59.F.(2), 77.J.(1), UK76, and also IJ produced from their respective crosses. For each isolate or cross, $40 \mathrm{G}$. mellonella were divided equally among four $9 \mathrm{~cm}$ diam. Petri dishes lined with moist $9 \mathrm{~cm}$ filter paper $(10 \mathrm{G}$. mellonella per dish). For each isolate or cross, $2 \mathrm{ml}$ of IJ suspension (1000 $\mathrm{IJ} \mathrm{ml}^{-1}$ ) was pipetted into each of the Petri dishes, and then incubated at $20^{\circ} \mathrm{C}$. After 3 days, seven randomly selected $G$. mellonella cadavers per cross progeny were dissected each day in quarter-strength Ringer solution until progeny were observed in a total of seven cadavers per selfing or cross. No attempt was made to identify the juvenile stage of the progeny. A mean time until observation of any progeny was then calculated for each cross or selfing. Differences in the mean time until progeny were observed were calculated using the Kruskal-Wallis test.

\section{Assessment of insect mortality}

The ability of all five parent isolates (1.E.(1), 33.D.(2), 59.F.(2), 77.J.(1) and UK76) and their crosses to kill $G$. mellonella larvae was assessed. One-on-one infections were performed in $1.5 \mathrm{ml}$ microcentrifuge tubes as described by Rolston et al. (2006). No larva received more than one nematode. The tubes were placed at $20^{\circ} \mathrm{C}$ for 5 days and then the mortality of $G$. mellonella was scored. The tubes were placed back at $20^{\circ} \mathrm{C}$ for a further 5 days, when insect mortality was scored again. This was repeated for each parent isolate and each cross progeny. Comparisons between parent isolates and their respective crosses were made using two-proportion tests. Comparisons between rank order of isolates and crosses after 5 and 10 days were made using Spearman Rank Correlation.

\section{MOLECULAR $\beta$-TUBULIN ANALYSIS OF NEMATODE POPULATIONS}

Nematode isolates (Table 1) were cultured in G. mellonella larvae as described above. Seven days after inoculation, the infected cadavers were transferred to White traps to collect emerging infective juveniles. IJ were harvested each day for 7 days following first emergence. Each day's harvest was pooled, washed in distilled water and allowed to settle in their container. The supernatant was discarded and $1 \mathrm{ml}$ of the concentrated nematode suspension was pipetted into a $1.5 \mathrm{ml}$ microcentrifuge tube and centrifuged (Eppendorf centrifuge, 5415D) at $16000 \mathrm{~g}$ for $5 \mathrm{~min}$. The supernatant was again discarded and the nematode pellet (approximately $500 \mathrm{mg}$ 
wet weight) stored at $-20^{\circ} \mathrm{C}$ until further use. The pellet was semi-defrosted and the nematodes ground in the tube by agitation using a sterilised blunt-ended mounted needle. The DNA of these isolates, plus a negative control, Caenorhabditis elegans, was then extracted using a Qiagen Dneasy animal tissue kit (Qiagen, Hilden, Germany).

The PCR reaction was performed in a PTC-200 thermal cycler (Bio-Rad Laboratories, Waltham, MA, USA), using S. feltiae $\beta$-tubulin EPIC-PCR primers (Boyle $e t$ al., unpubl.). The PCR program for DNA amplification was as follows. Ten min of denaturing at $94^{\circ} \mathrm{C}, 3$ cycles of $30 \mathrm{~s}$ denaturing at $94^{\circ} \mathrm{C}, 30 \mathrm{~s}$ annealing at $55^{\circ} \mathrm{C}$ and $30 \mathrm{~s}$ extension at $72^{\circ} \mathrm{C} ; 35$ cycles of $30 \mathrm{~s}$ denaturing at $94^{\circ} \mathrm{C}, 30 \mathrm{~s}$ annealing at $58.2^{\circ} \mathrm{C}$ and $30 \mathrm{~s}$ extension at $72^{\circ} \mathrm{C}$; 5 min extension at $72^{\circ} \mathrm{C}$. Verification of the PCR products was performed in $2.2 \%$ agarose gel stained with ethidium bromide $\left(0.5 \mu \mathrm{g} \mathrm{ml}^{-1}\right)$ in $0.5 \mathrm{TAE}$ buffer. The gel electrophoresis was run at $100 \mathrm{~V}$ for $1 \mathrm{~h}$ and $10 \mathrm{~min}$ and the gel was subsequently visualised using a Kodak DC290 camera, and the imaging program Kodak ID 3.5. Fresh PCR product was cloned using a TOPO TA cloning kit (Invitrogen, Carlsbad, CA, USA) and plasmid DNA was subsequently isolated using a QIAprep spin miniprep kit (Qiagen). The amplified DNA was sequenced by MWG Biotech (three clones per isolate) and then aligned using CLUSTALX (Thompson et al., 1997), and analysed using the maximum likelihood method, conducted using PAUP* 4.0b 10 (Swofford, 1996).

\section{STATISTICAL ANALYSES}

Statistical analyses were conducted using Minitab v13.1 and Statistix 8.

\section{Results}

\section{SPECIES IDENTIFICATION}

All Bull Island isolates were confirmed as S. feltiae following morphological studies and the production of viable offspring following cross-breeding with the commercial S. feltiae isolate, UK76.

\section{ASSESSMENT OF CROSS BREEDING}

All of the insects died as a result of the injection of IJ, with all dead insects showing typical symptoms of EPN infection. Only 50\% of cadavers would be expected to have received both a male and a female nematode. However, the number of cadavers that actually
Table 3. The number of Galleria melonella cadavers that showed infective juvenile (IJ) emergence after various crosses, 30 days after infection. Selfed isolates (isolates crossed with themselves) are italicised.

\begin{tabular}{|c|c|}
\hline Cross & $\begin{array}{l}\text { Number of replicates (out of a } \\
\text { probable } 20^{*} \text { ) showing emerging } \mathrm{IJ}\end{array}$ \\
\hline 1.E.(1) $\times$ 1.E.(1) & 11 \\
\hline 1.E.(1) × 77.J.(1) & 10 \\
\hline 77.J.(1) × UK76 & 10 \\
\hline$U K 76 \times U K 76$ & 9 \\
\hline 59.F. $(2) \times$ 59.F. $(2)$ & 6 \\
\hline 1.E.(1) $\times$ UK76 & 6 \\
\hline 33.D.(2) × 59.F.(2) & 3 \\
\hline 33.D. $(2) \times 33 . D .(2)$ & 1 \\
\hline 77.J.(1) × 77.J.(1) & 1 \\
\hline 1.E.(1) × 59.F.(2) & 1 \\
\hline 1.E.(1) × 33.D.(2) & 0 \\
\hline 33.D.(2) × 77.J.(1) & 0 \\
\hline 33.D. (2) $\times$ UK76 & 0 \\
\hline 59.F.(2) × UK76 & 0 \\
\hline 59.F.(2) × 77.J.(1) & 0 \\
\hline Total & 58 \\
\hline
\end{tabular}

* Only half of the replicate insects of any cross would have been expected to have received both a male and a female IJ. On that basis, out of 40 replicates of any cross, 20 replicates would have been expected to show reproduction (emerging IJ).

resulted in IJ emergence was significantly fewer than that expected, i.e., the number deviated significantly from the expected $50 \%$ of cadavers injected (one proportion test, $z=-19.76, P<0.001)$. There was great variation between crosses in the number of replicates that resulted in emerging IJ (Table 3). Isolate 1.E.(1) crossed with the greatest number of isolates and produced the highest number of cadavers exhibiting emerging IJ. Isolate 33.D.(2) crossed with the least number of isolates and produced the fewest number of cadavers exhibiting emerging IJ (Table 4). Thirty days post-infection, 82 intact cadavers that had not produced emerging IJ were randomly selected for dissection to examine reasons for their failure. Of the dissected cadavers, $36.6 \%$ (30/82) did not contain any adult nematodes (the injected IJ were not found). Of the dissected cadavers that did contain developed first generation adult nematode(s), 50\% $(25 / 52)$ contained only one nematode. Within these lone adults there was a $1: 1$ male to female ratio $\left(\chi^{2}=0.19\right.$, $d f=1, P>0.05$ ). Of these lone nematodes, $74.2 \%$ of males and $72.2 \%$ of females were dead. Live IJ that had failed to emerge were found in five cadavers upon 
dissection. The selfing 59.F.(2) $\times$ 59.F.(2) resulted in three of these cases. The only instance where all such unemerged progeny were dead was found in a selfing of 33.D.(2) $\times$ 33.D.(2). When selfed, the isolates 33.D.(2) and 77.J.(1) performed poorly with only one emergence for each isolate out of an expected 20.

\section{PROGENY NUMBERS}

There was great variability in the mean number of IJ emerging as a result of successful crosses. When selfed, UK76 and 1.E.(1) produced the highest mean number of emerged IJ, yet crossing these isolates with each other lead to a large decrease in the number of IJ emerging (Fig. 1). On no occasion did outcrossing UK76 or 1.E.(1) with any other isolate result in an increase in numbers of IJ emerging when compared with their respective selfings. Five crosses failed to produce any progeny at all. Three

Table 4. Number of isolates (including selfs) of Steinernema feltiae with which each isolate crossed successfully, and cadavers producing emergences.

\begin{tabular}{lcc}
\hline Isolate & $\begin{array}{c}\text { Number of successful } \\
\text { crosses (out of five) }\end{array}$ & $\begin{array}{c}\text { Number (and percentage) } \\
\text { of emergences } \\
\text { (out of a possible 200) }\end{array}$ \\
\hline 1.E.(1) & 4 & $28(14 \%)$ \\
UK76 & 3 & $25(12.5 \%)$ \\
77.F.(1) & 3 & $21(10.5 \%)$ \\
59.F.(2) & 3 & $10(5 \%)$ \\
33.D.(2) & 2 & $4(2 \%)$ \\
\hline
\end{tabular}

of these failed crosses involved isolate 33.D.(2) and the remaining two involved isolate 59.F.(2). Only crosses that produced emergence could be used to assess both the time taken to produce second generation and insect mortality.

\section{TIME TAKEN TO PRODUCE PROGENY}

There was significant difference between isolates for the mean number of days until progeny were observed within host insect cadavers (Kruskal-Wallis test: $F=$ 42.1, $d f=97, P<0.001$ : Fig. 2). The highest and lowest median values were 7 days (59.F.(2) $\times 59$.F.(2)) and 4 days (the seven crosses with the lowest values shown in Fig. 2), respectively. Progeny of the cross $33 . \mathrm{D}(2) \times 59 . \mathrm{F}(2)$ failed to kill any insects and so no second generation juveniles were observed. The overall mean number of days until second generation juveniles were observed was $4.91 \pm 0.11$ days. Isolate 1.E.(1) and any cross involving it produced second generation juveniles after 4 days, with no measured variation. Outcrosses and selfing involving UK76 produced second generation individuals quicker than the stock UK76 isolate. Except when crossed with 1.E(1), isolates 33.D.(2) and 59.F.(2) consistently took longer than the mean number of days to produce second generation juveniles.

\section{ASSESSMENT OF INSECT MORTALITY}

Three of the five stock isolates, UK76, 1.E.(1) and 77.J.(1), produced the highest percentage of insect mortality (Fig. 3). When crossed together, 1.E.(1) and 77.J.(1)

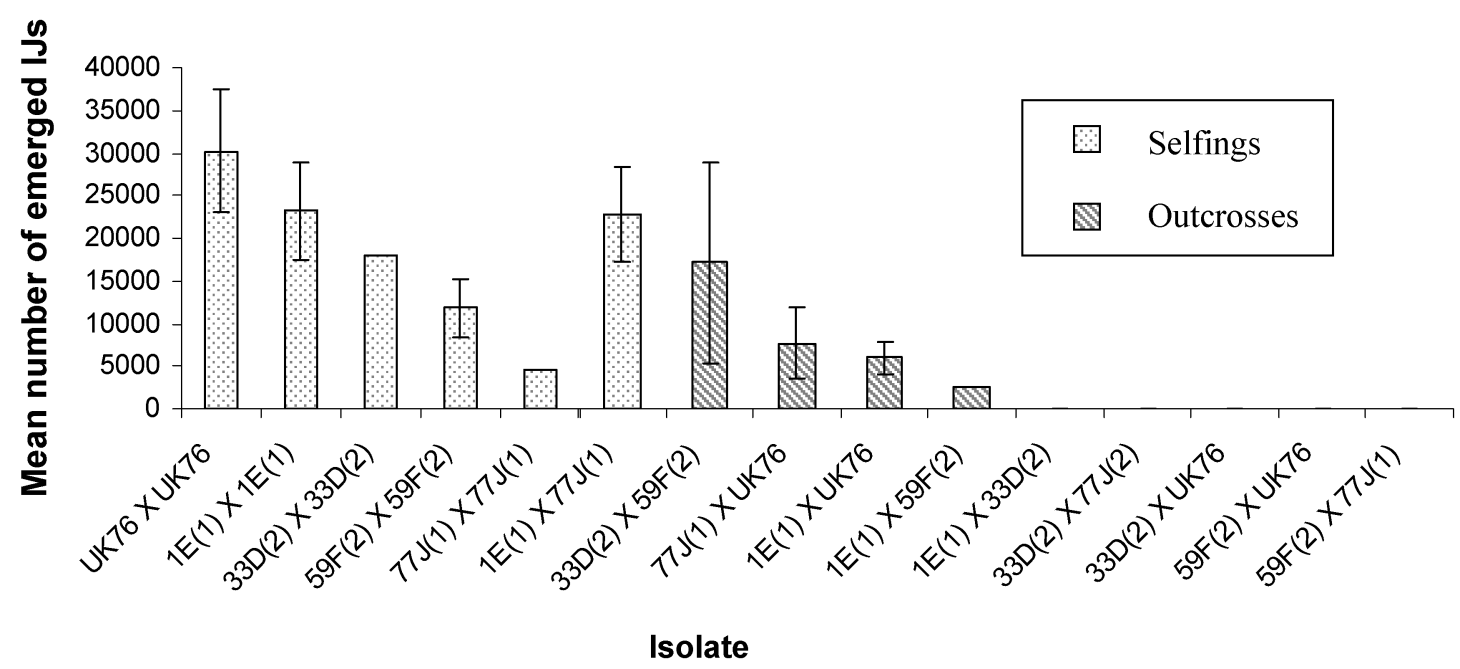

Fig. 1. Mean number per fertile cadaver ( \pm standard error) of Steinernema feltiae infective juveniles emerging from Galleria mellonella cadavers after cross-breeding. Data without error bars are the result of only one successful emergence. 


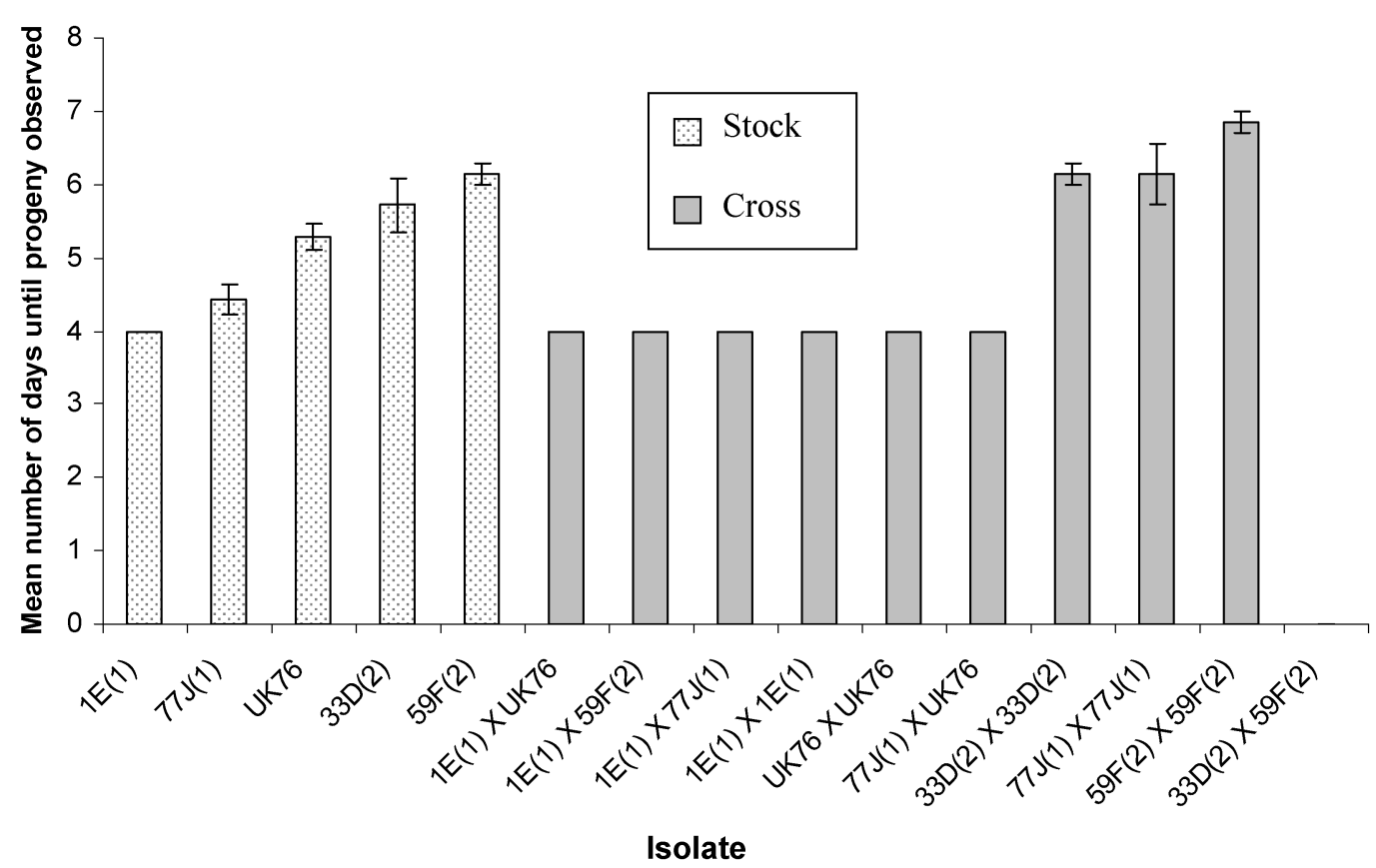

Fig. 2. The mean ( \pm standard error) number of days until second generation juveniles of various stock Steinernema feltiae isolates and their crosses were observed inside Galleria mellonella cadavers. Data without error bars showed no variation in the number of days taken for progeny to be observed $(n=7$ per cross). No emerging progeny were observed for the cross $33 . D .(2) \times 59 . F .(2)$.

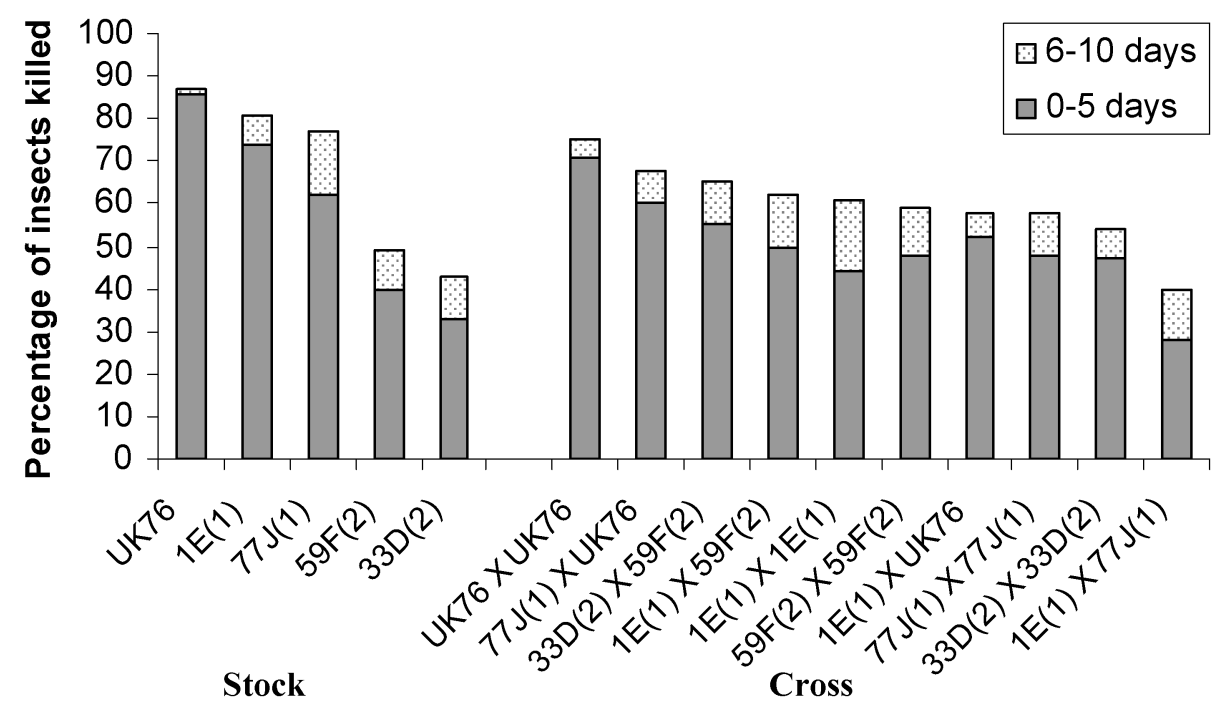

Fig. 3. Percentage of Galleria mellonella killed after 5 and 10 days of one-on-one infection with stock isolates and their various crosses of Steinernema feltiae isolates.

caused the lowest percentage insect mortality. Stock isolates 33.D.(2) and 59.F.(2) had the second and third lowest number of insect kills respectively. The progeny of 33.D.(2) $\times$ 59.F.(2) killed significantly more insects than either of their respective parent isolates (two proportion tests: $z=2.98, P<0.01 ; z=2.14, P<0.05$, respectively). By contrast, the IJ produced from crosses involving UK76, 1.E.(1) and 77.J.(1) all killed significantly fewer insects than their parents (two proportion tests: $P=0.05$ or lower). Of the 937 insects that died, 
$798(85 \%)$ died within 5 days. The rank order for number of insects killed by each stock isolate or subsequent crosses was significantly different after 5 days than after 10 days (Spearman rank correlation, $P=0.0562$ ).

The crosses can be ranked on the basis of each of the three fitness criteria tested above. The sum of the ranks and the mean rank for each cross was calculated on the assumption that the fitness criteria are of equal importance. On this basis, the cross with the lowest mean rank (i.e., ranked first and therefore the best performing isolate) was UK76 $\times$ UK76, followed by the lowest ranking Bull Island isolate, 1.E.(1) $\times$ 1.E.(1).

\section{MOLECULAR $\beta$-TUBULIN ANALYSIS OF STEINERNEMA FELTIAE POPULATIONS}

PCR fragments ranged in size from 414-523 bp. Phylogenetic relationships were inferred using the pooled $\beta$-tubulin sequences of each isolate. The outgroup taxon sequence (C. elegans) was extracted from Genbank. Results of maximum likelihood analysis carried out using Paup* 4.0b are shown in Figure 4; C. elegans is separated from all other isolates tested. The two isolates 33.D.(2) and 59.F.(2) are distinct from the other isolates tested with 99\% support for this grouping. The remaining ten isolates are separated, again with strong bootstrap support (84\%), into three clades and, interestingly, Bull Island isolate 4.G.(1) is grouped with the two outgroups from Counties Kildare and Carlow. Both the commercial isolate, UK76 and Bull Island isolate 2.G.(1), are separated from the other isolates with at least $62 \%$ bootstrap support. The separation of $C$. elegans from the S. feltiae isolates, and 33.D.(2) and 59.F.(2) from the remaining Bull Island isolates is highlighted in the evolutionary distance between these two isolates and the remaining ten isolates (Fig. 5).

\section{Discussion}

Laboratory adaptation has been shown to produce dramatic changes in important biological attributes of EPN, such as storage stability, virulence and reproductive potential (Stuart \& Gaugler, 1996; Wang \& Grewal, 2002; Bai et al., 2005). Inadvertent selection of traits (Roush, 1990) and the deterioration of the bacterial symbiont (Bil-

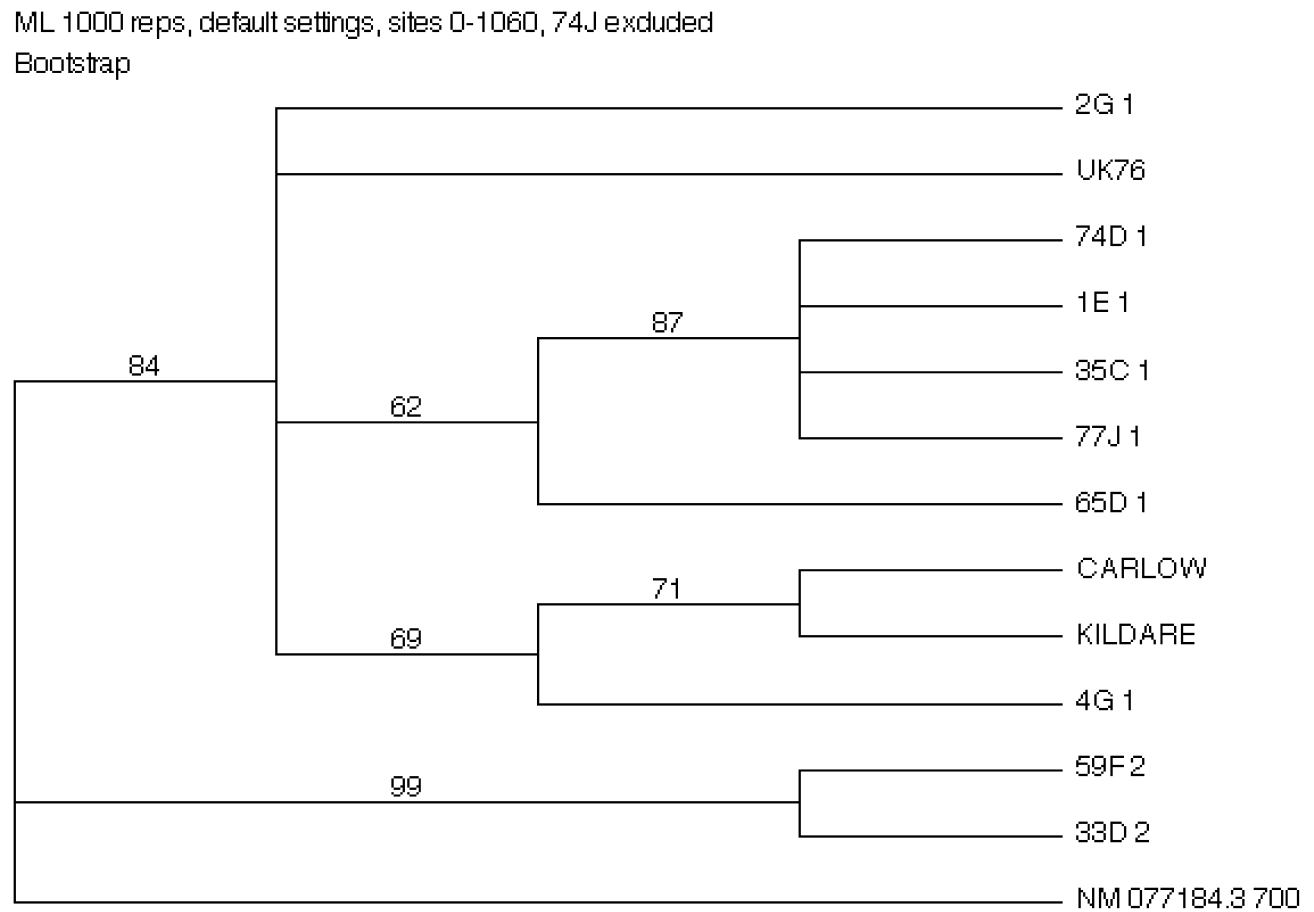

Fig. 4. Maximum likelihood phylogenetic tree, based on the sequence of a portion of the $\beta$-tubulin gene, of 12 Steinernema feltiae samples: nine from Bull Island, Dublin Bay, one isolate from County Carlow, Ireland, one isolate from County Kildare, and one commercial isolate from the $U K(U K 76)$. 
Maximum Likelihood, NNI, default settings, sites $1060+$ exduded

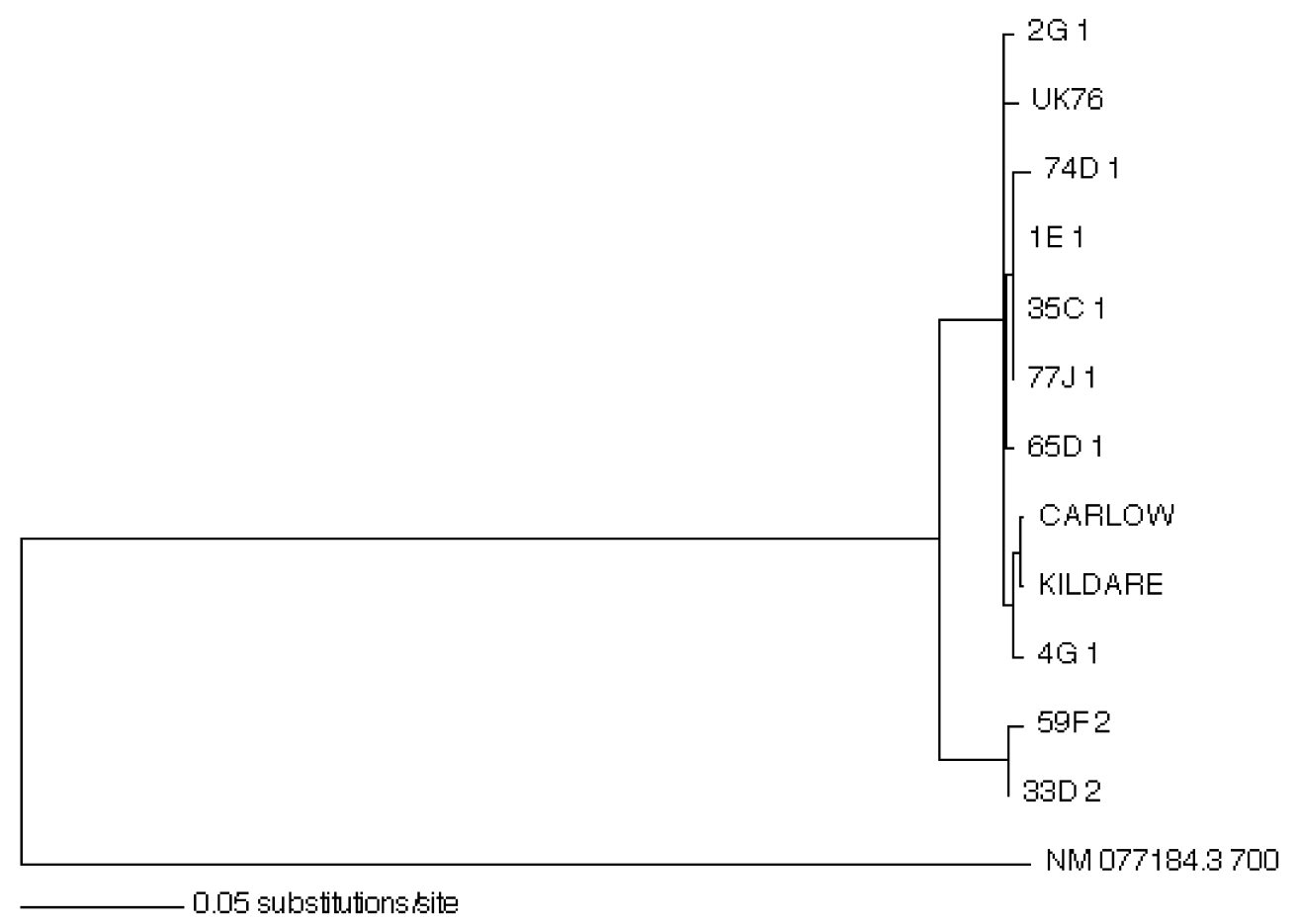

Fig. 5. Maximum likelihood phylogenetic tree, based on the sequence of a portion of the $\beta$-tubulin gene, showing branch lengths representing evolutionary distance between samples. Sample NM 077184.3700 is the Caenorhabditis elegans outgroup.

grami et al., 2006) when culturing nematodes in the laboratory is also likely to be important. The various isolates of $S$. feltiae used in our study were collected in different years and have subsequently been reared through G. mellonella in the laboratory for different time periods. Such culturing and possible inadvertent selection of IJ may have accentuated some of the behavioural and genetic variability observed in this study. Such variability may have arisen due to differing selection pressures acting within varying microhabitats on Bull Island. Somasekhar et al. (2002) suggest that high genetic variability among natural populations of $S$. carpocapsae may aid the feasibility of using selection for the genetic improvement of traits such as stress tolerance, virulence and reproductive potential. Attempts at genetic selection of EPN have been made (Segal \& Glazer, 2000; Strauch et al., 2004) and the genetic improvement of $S$. feltiae is an attractive proposal as $S$. feltiae is well studied and field tested and is used to control insect pests worldwide (Gaugler et al., 1989; Grewal, 2002). The use of molecular techniques to identify intraspecific differences that may reflect different biolog- ical characters might provide foundation populations for selecting positive characteristics (Liu et al., 2000). However, Gaugler et al. (1994) warn that, although genetic selection for advantageous traits may be an attractive theory, laboratory-selected strains have rarely been shown to be effective in the field.

Of the S. feltiae isolates tested here, 33.D.(2) and 59.F.(2) and their crosses consistently performed poorly in all fitness traits investigated. Although we are not suggesting that any molecular differences shown in this study are the cause of any behavioural traits, it is significant that both 33.D.(2) and 59.F.(2) have been shown to be molecularly distinct from other Bull Island $S$. feltiae with regards to their $\beta$-tubulin intron sequence. Reid and Hominck (1992) identified two RFLP types of S. feltiae: A1 and A2. It is certainly possible that both 33.D.(2) and 59.F.(2) differ in their RFLP type from the other $S$. feltiae isolates tested here and this needs further investigation. The bacterial preferences of 33.D.(2) and 59.F.(2) may also differ from the other $S$. feltiae isolates investigated here. Boszormenyi et al. (2001) showed that two isolates of $H$. downesi 
were each unable to utilise the other's symbiotic bacteria, despite these isolates being indistinguishable in both their morphology (Stock et al., 2002) and RFLP patterns (Pamjav et al., 1999). Isolates 33.D.(2) and 59.F.(2) may be similarly limited in their utilisation of the bacteria of other $S$. feltiae isolates, resulting in the restricted out-breeding of these two isolates highlighted in this study. Because of their inability to persist in culture, isolates 33.D.(2) and 59.F.(2) and their symbiotic bacteria, must differ from the other isolates (and respective bacteria) studied in their tolerance of environmental stress and inbreeding and other laboratory-induced factors.

The inability to invade successfully an insect may not necessarily inhibit an individual from reproducing and completing its life cycle. San-Blas and Gowen (2008) report that all of eight species of EPN, including $S$. feltiae, used scavenging as an alternative survival strategy and completed their life cycles in G. mellonella cadavers. This, as the authors suggest, could explain the long-term persistence of isolates such as 33.D.(2) and 59.F.(2) in the soil.

Laboratory adaptation can affect biological attributes of EPN (Stuart \& Gaugler, 1996; Wang \& Grewal, 2002). The cross-breeding of closely related individuals is known to have potential detrimental effects on the subsequent progeny. Phenotypic abnormalities that cause a decline in viability or fertility are often characteristics of inbred individuals (Perrin \& Goudet, 2001).

The culturing of the isolates tested here through many rounds of $G$. mellonella over time is likely to have increased inbreeding levels. Progeny of the 33.D.(2) $\times$ 59.F.(2) cross failed to invade and kill any host insects except when injected into insects, when not only were the hosts killed, but progeny emerged. It is possible that due to parental inbreeding and inadvertent selection, progeny were incapable of active host invasion and subsequent host mortality and EPN reproduction. However Bai et al. (2005) found that inbred lines of $H$. bacteriophora can prevent beneficial trait decline by causing greater mortality to host insects than foundation populations. Bilgrami et al. (2006) found that the loss of virulence against $G$. mellonella larvae was the result of bacterial deterioration during subculturing.

Isolates 33.D.(2) and 59.F.(2) were isolated on the second round of baiting of their respective soil samples with G. mellonella and have consistently performed poorly in behavioural assays other than presented here (Rolston, unpubl.). It is possible that they and their progeny need more than one exposure to host insects to initiate an infection response, and this option was not provided in these studies. However, it is questionable whether such an infection strategy would be viable in the field where potential host insects may be rare. Local or regional extinction appears to be a common phenomenon in ecological systems, and may affect the richness and population structure of many natural communities (Wright \& Coleman, 1993). Wilson et al. (2003) found that uniform inundative EPN application resulted in patchier distribution with time as nematodes died, whereas patchy application led to a more even distribution of EPN over time as the nematodes moved from their initial application. Extinction events in the field may not just be as a result of unsuitable insect host numbers, or environmental conditions (Hoy, 1976). In situations where hosts are rare, the chance of mating with a close relative increases. If this continues over several generations, inbreeding may lead to a decline in viability or fecundity that may in turn cause an extinction event. Founder effect is likely to play an important role in EPN genetic diversity (Roush, 1990; Gaugler, 1993). If local insect host numbers are few, numbers of EPN will decrease. A subsequent increase in the number of available insect hosts would lead to a recovery, in terms of numbers, in the local EPN population. However, the EPN population would have passed through an evolutionary bottleneck due to restricted founder numbers and so the new EPN population is likely to contain a lower genotypic diversity compared to the original population. EPN may be an ideal organism for studying inbreeding effects due to their ability to withstand high mortality rates, their short generation time and the large numbers of progeny produced per generation.

The fact that the majority of crosses failed to produce the expected number of emergences suggests that: i) all the isolates are somewhat inbred and, therefore, have reduced fitness; ii) the IJ were sensitive to the injection procedure and many were unable to survive the induced stress and the host's immune response (although this could also be a result of the first hypothesis) and iii) a breeding barrier exists between conspecifics. Nearly all species populations exhibit some degree of genetic differentiation among geographic localities (Ehrlich \& Raven, 1969), yet frequently, little variation in a given gene is uncovered when examining individuals in a species. Rosenthal (2001) outlines two hypotheses regarding such lack of variation: $i$ ) the gene's function is critical and the gene is therefore no longer subject to improvement or change, and chance could only give rise to individuals that would be at a selective disadvantage; $i i$ ) the lack of variation may 
be the result of present or past restrictions in the population size: variation in small or young populations is limited to the variability of the population's founders. The idea of fixed optimal infection strategies has been questioned by Crossan et al. (2007). For example, the fastest infecting IJ may not be the fittest as it may respond poorly to other fitness traits. Parasites may adapt their infection behaviour in an attempt to increase their chances of transmission within a given environment. Crossan et al. (2007) showed that the infection rate of $S$. feltiae was able to evolve rapidly in response to changes in the rate of host availability. However, there is likely to be a trade off in fitness between being highly infective and surviving in the soil for prolonged periods of host absence. Different intraspecific strains with differing optimum infection strategies may, therefore, exist within a population (Crossan $e t$ al., 2007). Dix et al. (1992) report reproductive incompatibility resulting from inter-strain crosses of $H$. bacteriophora, but this is seemingly unreported in intraspecific populations of Steinernema. Reproductive incompatibility has been well documented in mites and insects, particularly as a result of infection with Wolbachia bacteria (e.g., Werren, 1997; Navajas et al., 2000; Perez \& Hoy, 2002; Vala et al., 2002). Wolbachia bacteria have been found to be widespread in several filarial nematodes (Sironi et al., 1995; Taylor \& Hoerauf, 1999; Stevens et al., 2001), but are yet to be found in EPN.

Given the recent geological origin of Bull Island and the small geographical distances between isolates, the molecular and behavioural intraspecific variation of $S$. feltiae is unexpected. The phylogeny inferred from $\beta$-tubulin sequences suggests the possibility of two, perhaps three, separate colonisation events of Bull Island. The importation of soil with new genetic lines of EPN is certainly feasible through: $i$ ) the high level of human traffic that use the island for recreational purposes; $i$ ) the migration habits of many of the wildfowl and wading birds that over-winter on the island; and iii) animal activity between the mainland and the island via the connecting causeway. Comparisons between the Bull Island populations and those isolated from the nearby mainland coastline are yet to be made but may provide important information with regard to the importation of new genetic lines to the island. A shared colonisation origin on Bull Island is the most likely explanation for the genetic similarity of the widely separated $1 \mathrm{E}(\mathrm{I})$ and $75 \mathrm{~J}(\mathrm{I})$ (distance between soil cores $761.64 \mathrm{~m}$ ); however, it is also possible that sand transported by human activities may have given rise to this disjunct in distribution. In terms of unaided dispersal, the chance of direct gene flow between two populations from either end of the $800 \times 100 \mathrm{~m}$ sample area of Rolston $e t$ $a l$. (2005) is low. The greater the geographic distance between populations, the smaller chance of gene flow, which may eventually give rise to genetic isolation by distance (Page \& Holmes, 1998). The fact that for some species of nematodes there is no correlation between geographical and genetic distances (Hawdon et al., 2001) suggests that this topic needs further investigation for the isolates tested here, and for EPN in general.

The different microhabitats of the dune system of Bull Island may be a substantial cause of the variation observed between isolates as spatially varying selection can maintain substantial variability, making adaptations to the different habitat conditions possible (Barton, 2000). Information on gene flow between EPN populations is sorely lacking (see Blouin et al., 1999) and is in need of urgent investigation in order to attempt to estimate both the natural diversity of EPN populations and the potential impact of introduced alien or commercially applied nematodes on natural populations in the soil. The EPN populations of Bull Island may be ideal for an extended study of the level of gene flow within each of the two species that exist there due to their seemingly patchy population structures and the variable habitats within the dune system itself (Rolston et al., 2005).

This study has highlighted the significance of intraspecific variation in the population dynamics of EPN. However, it is important to recognise that each Bull Island isolate was possibly established from perhaps no more than two IJ. These successful IJ may not be representative of the population as a whole. Liu et al. (2000) importantly state that phylogenetic information is critical to rational implementation and monitoring programmes when EPN are used as biological control agents. When attempting to identify new EPN isolates for the potential control of insect pests, the results presented here agree with Roush (1990), that it is important to consider three genetic problems frequently inflicted by laboratory isolation: $i$ ) founder effect, where due to small initial sampling sizes, there is little genetic variation in the new population; ii) inbreeding depression, which is most apparent in small populations; iii) inadvertent selection, where due to laboratory rearing, field-selected adaptations become rare.

\section{Acknowledgements}

This research was funded by the EMBARK initiative, funded by the Irish Council for Science, Engineering 
and Technology (IRCSET). We thank Dublin Corporation and Pat Corrigan for permission to sample at North Bull Island.

\section{References}

Bai, C., Shapiro-Ilan, D., Gaugler, R. \& Hopper, K.R. (2005). Stabilization of beneficial traits in Heterorhabditis bacteriophora through creation of inbred lines. Biological Control 32, 220-227.

BARTON, N.H. (2000). Adaptation at the edge of a species' range. In: Silvertown, J. \& Antonovics, J. (Eds). Integrating ecology and evolution in a spatial context. London, UK, Blackwell Science Ltd, pp. 365-392.

Bilgrami, A.I., Gaugler, R., Shapiro-Ilan, D.I. \& ADAMS, B.J. (2006). Source of trait deterioration in entomopathogenic nematodes Heterorhabditis bacteriophora and Steinernema carpocapsae during in vivo culture. Nematology 8, 397-409.

Blouin, M.S., LiU, J. \& Berry, R.E. (1999). Life cycle variation and the genetic structure of nematode populations. Heredity 83, 253-259.

Boszormenyi, E., Lengyel, K., Oravecz, O., Szallas, E., Furgani, G. \& Fodor, A. (2001). Gnotobiological analysis of entomopathogenic nematode/bacterium symbiotic complexes. In: Griffin, C.T., Burnell, A.M., Downes, M.J. \& Mulder, R. (Eds). COST Action 819: Developments in entomopathogenic nematode/bacterial research. Brussels, Belgium, European Commission, p. 312.

Costa, J.C.R., Dias, R.J.P. \& Morenz, M.J.F. (2007). Determining the adaptation potential of entomopathogenic nematode multiplication of Heterorhabditis riobravis and Steinernema carpocapsae (Rhabditida: Heterorhabditidae, Steinernematidae) in larvae of Alphitobius diaperinus (Coleoptera: Tenebrionidae) and Galleria mellonella (Lepidoptera: Pyralidae). Parasitology Research 102, 139-144.

Crossan, J., Paterson, S. \& Fenton, A. (2007). Host availability and the evolution of parasite life-history strategies. Evolution 61, 675-684.

Dillon, A.B., Rolston, A.N., Meade, C.V., Downes, M.J. \& GRIFFIN, C.T. (2008). Establishment, persistence, and introgression of entomopathogenic nematodes in a forest ecosystem. Ecological Applications 18, 735-747.

DiX, I., Burnell, A.M., GrifFin, C.T., JOYCE, S.A. \& NUGENT, M.J. (1992). The identification of biological species in the genus Heterorhabditis (Nematoda: Heterorhabditidae) by cross breeding second-generation amphimictic adults. Parasitology 104, 509-518.

EHRLICH, P.R. \& RAVEN, P.H. (1969). Differentiation of populations. Science 165, 1228-1232.

FEnton, A. \& Hudson, P.J. (2002). Optimal infection strategies: should macrophages hedge their bets? Oikos 96, 92-101.
France, S.C., Tachino, N., Duda, T.F., Shleser, R.A. \& PAlumbi, S.R. (1999). Intraspecific genetic diversity in the marine shrimp Penaeus vannamei: Multiple polymorphic elongation factor-1 alpha loci revealed by intron sequencing. Marine Biotechnology 1, 261-268.

GAUGLER, R. (1993). Ecological genetics of entomopathogenic nematodes. In: Bedding, R., Akhurst, R. \& Kaya, H.K. (Eds). Nematodes for the biological control of insects. East Melbourne, Australia, CSIRO, pp. 89-95.

GAugler, R. \& KAYA, H.K. (1990). Entomopathogenic nematodes in biological control. Boca Raton, FL, USA, CRC Press Inc., 384 pp.

Gaugler, R., McGuire, T. \& Campbell, J. (1989). Genetic variability among strains of the entomopathogenic nematode Steinernema feltiae. Journal of Nematology 21, 247253.

Gaugler, R., Glazer, I., Campbell, J. \& Liran, N. (1994). Laboratory and field evaluation of an entomopathogenic nematode genetically selected for improved host finding. Journal of Invertebrate Pathology 63, 68-73.

GREWAL, P.S. (2002). Formulation and application technology. In: Gaugler, R. (Ed.). Entomopathogenic nematology. Wallingford, UK, CABI Publishing, pp. 265-287.

Grewal, P.S., Gaugler, R. \& Shupe, C. (1996). Rapid changes in thermal sensitivity of entomopathogenic nematodes in response to selection at temperature extremes. Journal of Invertebrate Pathology 68, 65-73.

GRIFFIN, C.T., MOORE, J.F. \& DOWNES, M.J. (1991). Occurrence of insect-parasitic nematodes (Steinernematidae, Heterorhabditidae) in the Republic of Ireland. Nematologica 37, 92-100.

HAWDON, J.M., Li, T., ZHAN, B. \& BloUin, M.S. (2001). Genetic structure of populations of the human hookworm, Necator americanus, in China. Molecular Ecology 10, 14331437.

He, M. \& HAYMER, D.S. (1997). Polymorphic intron sequences detected within and between populations of the Oriental Fruit Fly (Diptera: Tephritidae). Annals of the Entomological Society of America 90, 825-831.

HoY, M.A. (1976). Genetic improvements of insects: fact or fantasy. Environmental Entomology 5, 833-838.

Joyce, S.A., GrifFin, C.T. \& Burnell, A.M. (1994). The use of isoelectric focussing and polyacrylamide gel electrophorisis of soluble proteins in the taxonomy of the genus Heterorhabditis (Nematoda: Heterorhabditidae). Nematologica 40, 601-612.

LESSA, E. (1992). Rapid surveying of DNA sequence variation in natural populations. Molecular Biological Evolution 9, 323-330.

LIU, J. \& BERRY, R.E. (1996). Phylogenetic analysis of the genus Steinernema by morphological characters and randomly amplified polymorphic DNA fragments. Fundamental and Applied Nematology 19, 463-469. 
LiU, J., Berry, R.E. \& Moldenke, A.F. (1997). Phylogenetic relationships of entomopathogenic nematodes (Heterorhabditidae and Steinernematidae) inferred from partial $18 \mathrm{~S}$ rRNA gene sequences. Journal of Invertebrate Pathology 69, 246-252.

LiU, J., Poinar JR., G.O. \& Berry, R.E. (2000). Control of insect pests with entomopathogenic nematodes: The impact of molecular biology and phylogenetic reconstruction. Annual Review of Entomology 45, 287-306.

NAVAJAs, M., Tsagkarakov, A., LAgnel, J. \& PerrotMinnot, M.J. (2000). Genetic differentiation in Tetranychus urticae (Acari: Tetranychidae): polymorphism, host races or sibling species? Experimental and Applied Acarology 24, 365-376.

NguYen, K.B., MaruniaK, J. \& AdAms, B.J. (2001). Diagnostic and phylogenetic utility of the rDNA internal transcribed spacer sequences of Steinernema. Journal of Nematology 33, 73-82.

PAGE, R.D.M. \& HoLMES, E.C. (1998). Molecular evolution, a phylogenetic approach. Oxford, UK, Blackwell Science Ltd, $352 \mathrm{pp}$.

PALUMBI, S.R. \& BAKER, C.S. (1994). Contrasting population structure from nuclear intron sequences and mtDNA of humpback whales. Molecular Biological Evolution 11, 426435.

PAmjaV, H., Triga, D., BuZÁs, Z., Vellai, T., LuCskai, A., Adams, B., Reid, A.P., Burnell, A., Griffin, C., Glazer, I., Klein, M.G. \& Fodor, A. (1999). Novel application of PhastSystem polyacrylamide gel electrophoresis using restriction fragment length polymorphism - internal transcribed spacer patterns of individuals for molecular identification of entomopathogenic nematodes. Electrophoresis 20, 1266-1273.

PEREZ, O.G. \& HoY, M.A. (2002). Reproductive incompatibility between two subspecies of Coleomegilla maculata (Coleoptera: Coccinellidae). Florida Entomologist 85, 203-207.

PERrin, N. \& Goudet, J. (2001). Inbreeding, kinship, and the evolution of natal dispersal. In: Clobert, J., Danchin, E., Dhondt, A.A. \& Nichols, J.D. (Eds). Dispersal. Oxford, UK, Oxford University Press, pp. 123-142.

PETERS, A. (1996). The natural host range of Steinernema and Heterorhabditis spp. and their impact on insect populations. Biocontrol Science and Technology 6, 389-402.

REID, A.P. \& HOMINICK, W.M. (1992). Restriction fragment length polymorphisms within the ribosomal DNA repeat unit of British entomopathogenic nematodes (Rhabditida: Steinernematidae). Parasitology 105, 317-323.

Reid, A.P., Hominick, W.M. \& BRISCOE, B.R. (1997). Molecular taxonomy and phylogeny of entomopathogenic nematode species (Rhabditida: Steinernematidae) by RFLP analysis of the ITS region of the ribosomal DNA repeat unit. Systematic Parasitology 37, 187-193.
Rolston, A.N., Griffin, C.T. \& Downes, M.J. (2005). Distribution of entomopathogenic nematodes in an Irish sand dune system. Nematology 7, 259-266.

Rolston, A.N., GrifFin, C.T. \& Downes, M.J. (2006). Emergence and dispersal patterns of two isolates of the entomopathogenic nematode Steinernema feltiae. Journal of Nematology, 38, 221-228.

Rosenthal, B.M. (2001). Defining and interpreting intraspecific molecular variation. Veterinary Parasitology 101, 187200.

Roush, T.R. (1990). Genetic variation in natural enemies: critical issues for colonisation in biological control. In: Mackauer, M., Ehler, L.E. \& Roland, J. (Eds). Critical issues in biological control. Andover, UK, Intercept/VCH, pp. 263288.

SAN-BLAS, E. \& GowEN, S.R. (2008). Facultative scavenging as a survival strategy of entomopathogenic nematodes. International Journal for Parasitology 38, 85-91.

SEGAL, D. \& GLAZER, I. (2000). Genetics for improving biological control agents: the case for entomopathogenic nematodes. Crop Protection 19, 685-689.

Shapiro, D.I., Glazer, I. \& SEGAL, D. (1996). Trait stability and fitness of the heat tolerant entomopathogenic nematode Heterorhabditis bacteriophora IS5 strain. Biological Control 6, 238-244.

Shapiro-Ilan, D.I., Dutcher, J.D. \& Hatab, M. (2005). Recycling potential and fitness of steinernematid nematodes cultured in Curculio caryae and Galleria mellonella. Journal of Nematology 37, 12-17.

Sironi, M., BANDi, C., SACChi, L., Di SACCO, B., DAMIANI, G. \& GENCHI, C. (1995). Molecular evidence for a close relative of the arthropod endosymbiont Wolbachia in a filarial worm. Molecular and Biochemical Parasitology 74, 223-227.

Smits, P.H., Groenen, J.T. \& DE RAAY, G. (1991). Characterization of Heterorhabditis isolates using DNA restriction fragment length polymorphism. Revue de Nématologie 14, 445-453.

Somasekhar, N., Grewal, P.S. \& Klein, M.G. (2002). Genetic variability in stress tolerance and fitness among natural populations of Steinernema carpocapsae. Biological Control 23, 303-310.

SteVEns, L., Giordano, R. \& FiAlho, R.F. (2001). Malekilling, nematode infections, bacteriophage infection, and virulence of cytoplasmic bacteria in the genus Wolbachia. Annual Review of Ecological Systematics 32, 519-545.

Stock, S.P., Griffin, C.T. \& Burnell, A.M. (2002). Morphological characterisation of three isolates of Heterorhabiditis Poinar, 1976 from the 'Irish group' (Nematoda: Rhabditida: Heterorhabditidae) and additional evidence supporting their recognition as a distinct species, H. downesi n. sp. Systematic Parasitology 51, 95-106.

Strauch, O., OestergaArd, J., Hollmer, S. \& Ehlers, R.-U. (2004). Genetic improvement of the desication toler- 
ance of the entomopathogenic nematode Heterorhabditis bacteriophora through selective breeding. Biological Control 31, 218-226.

StUART, R.J. \& GAUGLER, R. (1996). Genetic adaptation and founder effects in laboratory populations of the entomopathogenic nematode Steinernema glaseri. Canadian Journal of Zoology 74, 164-170.

Swofford, D.L., Olsen, G.L., Waddell, P.J. \& Hillis, D.M. (1996). Phylogenetic inference. In: Hillis, D.M., Moritz, C. \& Mable, B.K. (Eds). Molecular systematics, 2nd edition. Sunderland, MA, USA, Sinauer Associates, pp. 407514.

Szalanski, A.L., TAYlor, D.B. \& Mullin, P.G. (2000). Assessing nuclear and mitochondrial DNA sequence variation within Steinernema (Rhabditida: Steinernematidae). Journal of Nematology 32, 299-233.

TAYlor, M.J. \& HoERAuf, A. (1999). Wolbachia bacteria of filarial nematodes. Parasitology Today 15, 437-442.

Thompson, J.D., Gibson, T.J., Plewniak, F., JeanmouGIN, F. \& Higgins, D.G. (1997). The ClustalX windows interface: flexible strategies for multiple sequence alignment aided by quality analysis tools. Nucleic Acids Research 24, 4876-4882.

Vala, F., Weeks, A., Claessen, D., Breeuwer, J.A.J. \& SABELIS, M.W. (2002). Within- and between-population variation for Wolbachia-induced reproductive incompatibility in a haplodiploid mite. Evolution 56, 1331-1339.

WANG, H. \& GREWAL, P.S. (2002). Rapid genetic deterioration of environmental tolerance and reproductive potential of an entomopathogenic nematode during laboratory maintenance. Biological Control 23, 71-78.

Werren, J.H. (1997). Biology of Wolbachia. Annual Review of Entomology 42, 587-609.

WHITE, G.F. (1927). A method for obtaining infective nematode larvae from cultures. Science 66, 302-303.

Wilson, M.J., Lewis, E.E., Yoder, F. \& Gaugler, R. (2003). Application pattern and persistence of the entomopathogenic nematode Heterorhabditis bacteriophora. Biological Control 26, 180-188.

WRIGHT, D.H. \& COLEMAN, D.C. (1993). Patterns of survival and extinction of nematodes in isolated soil. Oikos 67, 563572. 